\title{
Parameter optimization of a 3D coastal model using Green's functions for modelling river plume dynam-
}

\author{
ics

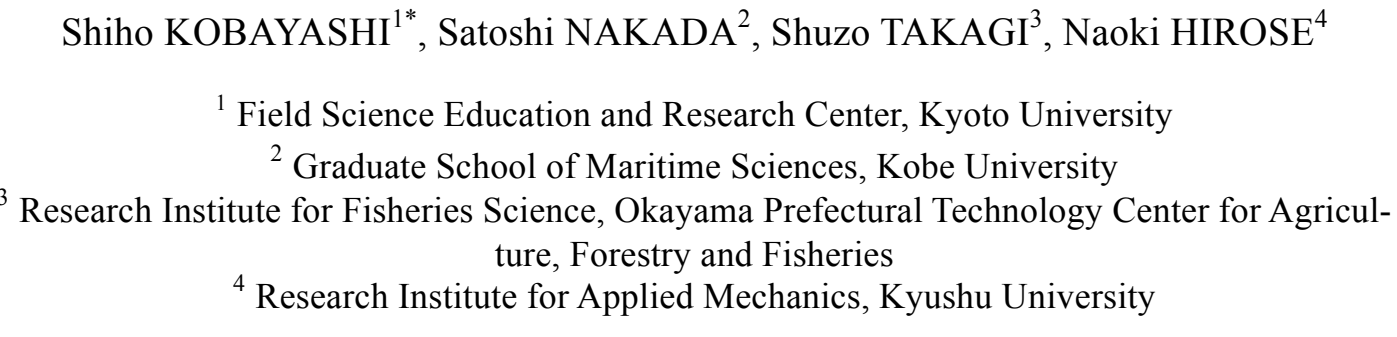 \\ *Shihok@kais.kyoto-u.ac.jp
}

Received: Feburary 3, 2016; Accepted: March 19, 2016; Published: April 7, 2017

\begin{abstract}
River plumes flowing into channels with strong tidal currents cause pulsed decreases in the salinity around the river mouth. This study constructs a numerical model for reproducing the river plumes of Asahi and Yoshii Rivers flowing into Bisan Seto, a tidal channel in the Seto Inland Sea. Recently inverse estimation of the model parameters using Green's functions has been applied to numerical modelling of sea shelves as a simple and effective method of parameter optimization. This paper examines the method that aims to improve the precision of the model results, but uses a model domain (ca. $50 \mathrm{~km}$ ) that is much smaller than in previous studies. The reproducibility of the tidal elevations and currents was improved significantly by the parameter optimization procedures. The reproducibility of the temporal changes in salinity was also improved, although they showed strong nonlinearity. These results indicate that the inverse estimation of model parameters using Green's functions can greatly improve the reproducibility of the modelling of river plumes flowing into tidal channels.
\end{abstract}

Keywords: River plume, Seto Inland Sea, Parameter optimization, Green's function

\section{Introduction}

In coastal seas with convoluted shorelines, tidal elevations and currents vary greatly. The 


\section{Journal of Advanced Simulation in Science and Engineering}

Seto Inland Sea, Japan, resembles an archipelago in that it has a number of narrow straits where strong tidal currents are generated. Any river plume flowing into such a strait is strongly influenced by tidal currents, and as a result, its flow paths change significantly and it quickly disperses. Bricker et al. [2] call such a river plume a "pulsed river plume".

The river plumes flowing into the Seto Inland Sea play an important role in supplying nutrients essential for seaweed culture, which is a major coastal industry. Takagi et al. [12] continuously monitored salinity at a number of stations in an area of seaweed culture in Okayama prefecture, and fully explored the pulsed river plume there. High-precision modelling of the river plume is the next step required if we are to forecast the supply of nutrients and so help to manage river discharge.

The most important element in the realistic reproduction of the tidal currents in the small-scale model domain is the accuracy of the tidal elevations given at the horizontal boundaries. Parameters such as bottom friction must be carefully selected to obtain precise tidal currents. Here, we use Green's functions to determine an optimal set of parameters for modelling river plumes, following the studies of Menemenlis et al. [8] and Hirose [5].

This method estimates the optimized values using linear least squares. Moon et al. [9] used this method and succeeded to reproduce tidal levels in East Asian marginal seas. The model domain in this study (ca. $50 \mathrm{~km}$ ) is much smaller than was used in these previous studies, and our aim here is to reproduce the pulsed change in salinity, which shows strong nonlinearity.

We examine here the applicability of using Green's functions in a small-scale coastal model, and evaluate the reduction of the cost functions. Through this approach we construct a numerical model to reproduce the river plumes of Asahi and Yoshii Rivers flowing into Bisan Seto, a tidal channel in the Seto Inland Sea.

\section{Model configuration and data for model optimization}

This study applies a numerical model, the Princeton Ocean Model with a generalized coordinate of sigma (POMgcs; [7]), which combines the $\mathrm{z}$ - and sigma-coordinate to simulate tidal currents and the salinity distribution. The model domain is shown in Figure 1b. This is the first case to apply POMgcs to simulate tidal currents and river plume around Kojima Bay, while tidal and residual currents in the Seto Inlans Sea are simulated using POM [3] in previous studies (e.g. [6, 4]). The Coriolis parameter is $8 \times 10^{-5} \mathrm{~s}^{-1}$ at a latitude of $34^{\circ}$. The horizontal grid size is $1 \mathrm{~km}^{2}$, and eight non-uniform sigma levels are used in the vertical direction. The depth data were obtained by smoothing from bathymetry data (ca. $500 \mathrm{~m}$ ) supplied by the Japan Ocean Data Center. Since the main aim of this study was to simulate tidal currents and river plume in a short time and to examine the applicability of the parameter optimization using Green's functions, the grid resolution was set to be a lower limit. The model 


\section{Journal of Advanced Simulation in Science and Engineering}

was forced by the four tidal constituents of surface height along the eastern and western open boundaries $\left(\mathrm{K}_{1}, \mathrm{O}_{1}, \mathrm{M}_{2}\right.$, and $\mathrm{S}_{2}$, shown by broken lines in Figure $\left.1 \mathrm{~b}\right)$. The tide data at eastern (Sanbonmatsu) and western (Marugame) boundaries were derived from harmonic constants data provided by the Japan Coast Guard. As the model aims to reproduce a river plume controlled mainly by tidal elevation and currents, we did not set wind as a driving force here.

Harmonic constants of tidal elevations and currents derived from five tide gauges (Ushimado, Kogushi, Uno, Jozozaki, Obe) and three current time series at $5 \mathrm{~m}$ from the surface (locations in Figure 1b) provided by the Japan Coast Guard were used for the optimization of the model. Salinity was measured every $10 \mathrm{~min}$ from $7^{\text {th }}$ to $31^{\text {st }}$ December 2007 by instruments moored at $0.5 \mathrm{~m}$ from the surface at 16 stations [12] and we used salinity data at stations 4 to 9 and 11 to 13 (locations in Figure 1c) for the optimization.

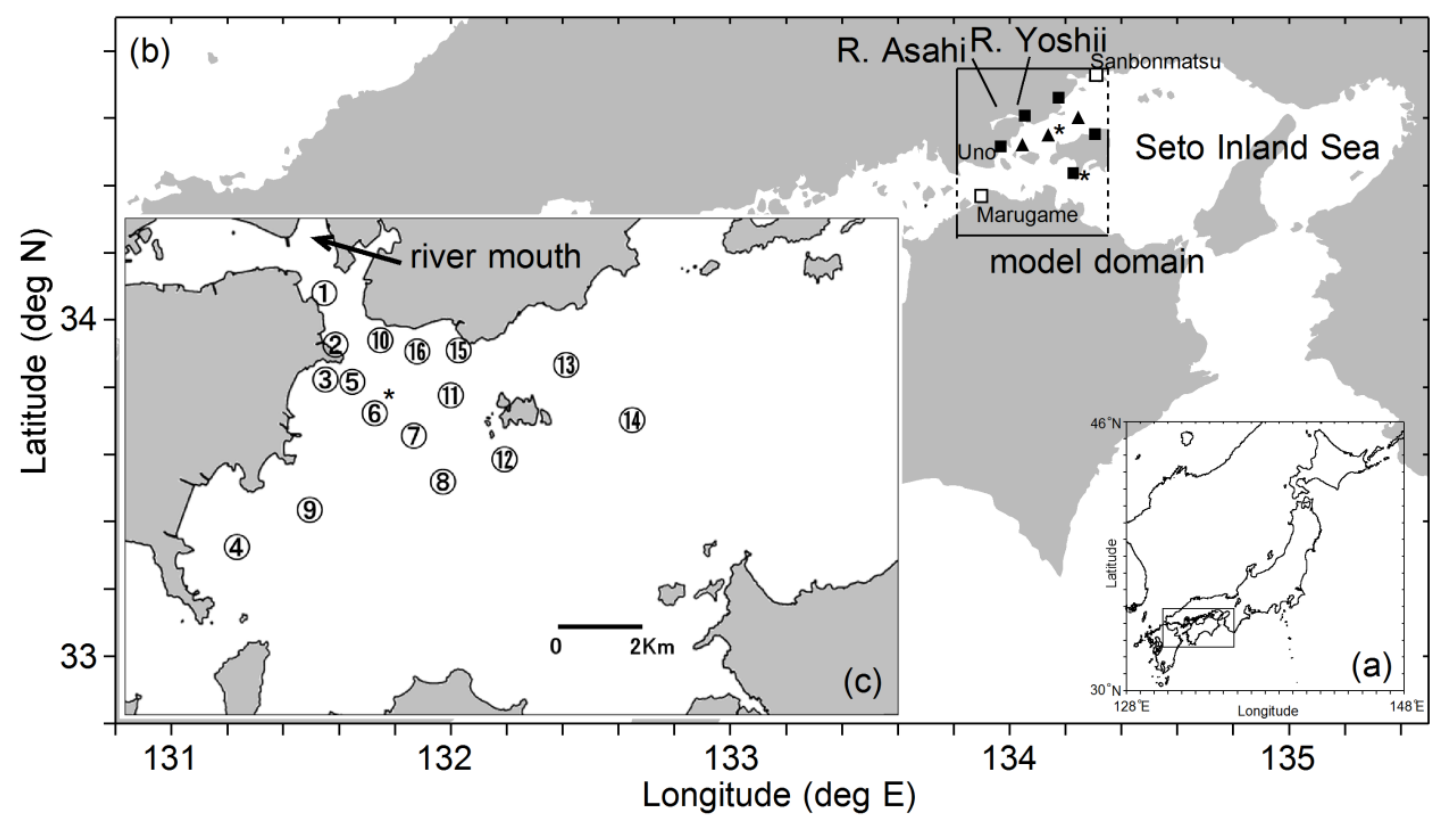

Figure 1: (a) Location and (b) map of the Seto Inland Sea. The computational domain is surrounded by a black border, and the eastern and western open boundaries are shown by broken lines. The triangles and rectangles indicate the locations of the stations where the harmonic constants of the tidal currents and tidal levels, respectively, were obtained. The white rectangles indicate data used for the boundary conditions, and the black rectangles indicate data used for the parameter optimization. (c) Enlarged view of the study area. The circles numbered 1-16 mark the salinity monitoring stations. Star marks (*) in Figures 1(b) and 1(c) show the stations where the modeled and observed results are shown in Figure 4.

Figure 2 shows an example of the observed salinity variation with tidal elevation (derived from the tide gauges) and daily mean river discharge (observed by the Ministry of Land, 
Journal of Advanced Simulation in Science and Engineering

Infrastructure Transport and Tourism). Salinity measured at all 16 stations showed pulsed decreases at every low tide, while several peaks coalesced into a single peak only when the river discharge increased (e.g., over the period 23-25 December 2007; Figure 2a). The magnitude of the decrease in salinity during neap tides was less than that associated with the spring tides, even though river discharge showed little variation over the neap-spring cycle.

The calculation period was set to one month from $1^{\text {st }}$ December 2007, and the calculated results after $10^{\text {th }}$ December were used for the optimization of the model and the discussion.
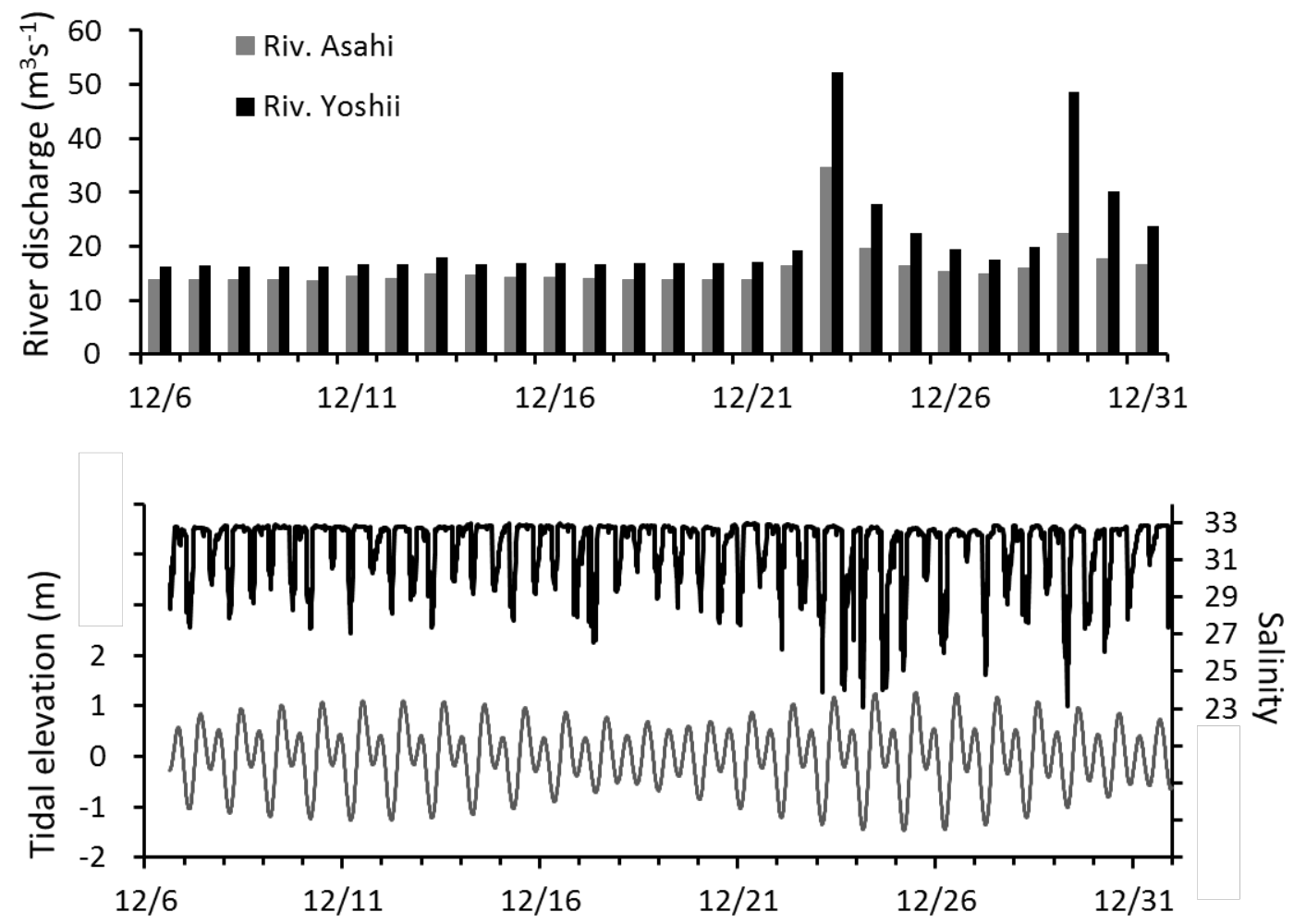

Figure 2: Temporal variations of (a) discharge $\left(\mathrm{m}^{3} \mathrm{~s}^{-1}\right)$ from the Asahi and Yoshii rivers (these locations are shown in Figure 1b). (b) Salinity observed at station 6 (shown in Figure 1c) and tidal elevations (m) over the period 7-31 December 2007.

\section{Parameter optimization using Green's functions}

We first conducted a baseline integration using the default physical parameters: horizontal eddy viscosity and diffusion, vertical eddy viscosity, bottom drag coefficient, and harmonic constituents obtained by observation described in Section 2 at the eastern and western open boundaries. We then conducted the sensitivity experiment with perturbations in both the bottom drag coefficient and the harmonic constituents along the open boundaries (Table 1). In 
Journal of Advanced Simulation in Science and Engineering

addition to these parameters, the stable increment of water level at the western boundary was also perturbed as a controllable factor, following the distribution of tidal energy flux in the Seto Inland Sea [6].

Table 1: List of sensitivity experiments

\begin{tabular}{|c|c|c|c|}
\hline Experiment & Parameter & Baseline & Perturbation \\
\hline 1 & $\mathrm{M}_{2}$ amplitude at western boundary (\%) & 100 & 90 \\
\hline 2 & $\mathrm{M}_{2}$ phase at western boundary $\left({ }^{\circ}\right)$ & 0 & -10 \\
\hline 3 & $\mathrm{~S}_{2}$ amplitude at western boundary (\%) & 100 & 90 \\
\hline 4 & $\mathrm{~S}_{2}$ phase at western boundary $\left({ }^{\circ}\right)$ & 0 & -10 \\
\hline 5 & $\mathrm{~K}_{1}$ amplitude at western boundary (\%) & 100 & 90 \\
\hline 6 & $\mathrm{~K}_{1}$ phase at western boundary $\left({ }^{\circ}\right)$ & 0 & -10 \\
\hline 7 & $\mathrm{O}_{1}$ amplitude at western boundary (\%) & 100 & 90 \\
\hline 8 & $\mathrm{O}_{1}$ phase at western boundary $\left(^{\circ}\right)$ & 0 & -10 \\
\hline 9 & $\mathrm{M}_{2}$ amplitude at eastern boundary (\%) & 100 & 90 \\
\hline 10 & $\mathrm{M}_{2}$ phase at eastern boundary $\left({ }^{\circ}\right)$ & 0 & -10 \\
\hline 11 & $\mathrm{~S}_{2}$ amplitude at eastern boundary (\%) & 100 & 90 \\
\hline 12 & $\mathrm{~S}_{2}$ phase at eastern boundary $\left(^{\circ}\right)$ & 0 & -10 \\
\hline 13 & $\mathrm{~K}_{1}$ amplitude at eastern $\mathrm{n}$ boundary $(\%)$ & 100 & 90 \\
\hline 14 & $\mathrm{~K}_{1}$ phase at eastern boundary $\left(^{\circ}\right)$ & 0 & -10 \\
\hline 15 & $\mathrm{O}_{1}$ amplitude at eastern boundary (\%) & 100 & 90 \\
\hline 16 & $\mathrm{O}_{1}$ phase at eastern boundary ${ }^{\circ}$ ) & 0 & -10 \\
\hline 17 & addition of water level at west. bound. (m) & 0.00 & 0.02 \\
\hline 18 & bottom drag coefficient $\left(\times 10^{-3}\right)$ & 2.6 & 3.6 \\
\hline
\end{tabular}

The differences between the baseline and sensitivity experiments essentially provide the column vectors of the Green's functions matrix [5]. Here, we created the Green's functions matrix for six cases using the combinations of selected datasets for tidal elevation, current, and salinity (optimizations A-F; Table 2).

The linear inversion method of Menemenlis et al. [8] was applied and the solutions for the 18 parameters for each optimization $\mathrm{A}-\mathrm{F}$ are given in Table 3 . The optimized bottom drag coefficients are all larger than the default value of $2.6 \times 10^{-3}$. The optimized increment of water level at the western boundary remained stable at $0.4-0.5 \mathrm{~cm}$ in all cases that used tidal currents and salinity to generate the Green's functions matrix (i.e., optimizations B-F). The 
Journal of Advanced Simulation in Science and Engineering

optimized amplitude and phases at the eastern and western open boundaries were determined with little variation among the cases. The solutions were independent of the values for perturbation in the sensitivity experiments (shown in Table 1), for example, the optimized values did not change when the values for perturbation were set to be $110 \%$ for the amplitude or +10 degree for the phases.

Table 2: List of optimizations

\begin{tabular}{ll}
\hline Case & Data used for making Green's functions matrix \\
\hline Baseline & - \\
Optimization A & tidal elevations \\
Optimization B & tidal currents \\
Optimization C & tidal elevations + tidal currents \\
Optimization D & salinity \\
Optimization E & salinity + tidal currents \\
Optimization F & tidal elevations + tidal currents + salinity \\
\hline
\end{tabular}

Table 3: Optimized values of factors and increments used to obtain optimized parameters for optimizations A-F (shown in Table 2).

\begin{tabular}{|c|c|c|c|c|c|c|}
\hline \multirow[b]{2}{*}{ Parameter } & \multicolumn{6}{|c|}{ Optimized values } \\
\hline & Op.A & Op.B & Op.C & Op.D & Op.E & Op.F \\
\hline $\mathrm{M}_{2}$ amplitude at west. bound. (\%) & 8.7 & 95 & 88 & 99 & 98 & 97 \\
\hline $\mathrm{M}_{2}$ phase at west. bound. ${ }^{\circ}$ ) & -5.1 & 2.0 & 0.2 & 0.1 & 0.0 & -0.5 \\
\hline $\mathrm{S}_{2}$ amplitude at west. bound. (\%) & 86 & 97 & 92 & 83 & 84 & 83 \\
\hline $\mathrm{S}_{2}$ phase at west. bound. $\left({ }^{\circ}\right)$ & -5.6 & 6.1 & -4.4 & 10.4 & 8.8 & 7.6 \\
\hline $\mathrm{K}_{1}$ amplitude at west. bound. (\%) & 100 & 91 & 104 & 97 & 95 & 100 \\
\hline $\mathrm{K}_{1}$ phase at west. bound. $\left(^{\circ}\right)$ & -4.8 & 1.2 & 2.2 & 0.7 & 0.0 & 1.5 \\
\hline $\mathrm{O}_{1}$ amplitude at west. bound. (\%) & 110 & 104 & 101 & 114 & 113 & 110 \\
\hline $\mathrm{O}_{1}$ phase at west. bound. $\left(^{\circ}\right)$ & -1.8 & -0.5 & 1.9 & 1.6 & 2.3 & 0.9 \\
\hline $\mathrm{M}_{2}$ amplitude at east. bound. (\%) & 93 & 117 & 96 & 108 & 108 & 104 \\
\hline $\mathrm{M}_{2}$ phase at east. bound. ${ }^{\circ}$ ) & -11.5 & -11.5 & -15.3 & -16.0 & -13.7 & -14.0 \\
\hline $\mathrm{S}_{2}$ amplitude at east. bound. (\%) & 101 & 106 & 100 & 156 & 149 & 148 \\
\hline $\mathrm{S}_{2}$ phase at east. bound. $\left(^{\circ}\right)$ & -26.5 & 19.5 & -25.6 & -7.7 & -5.0 & -9.1 \\
\hline $\mathrm{K}_{1}$ amplitude at east. bound. (\%) & 111 & 93 & 108 & 82 & 83 & 88 \\
\hline
\end{tabular}


Journal of Advanced Simulation in Science and Engineering

\begin{tabular}{|c|c|c|c|c|c|c|}
\hline $\mathrm{K}_{1}$ phase at east. bound. ${ }^{\circ}$ ) & -1.0 & -4.3 & -2.5 & -10.6 & -10.9 & -8.5 \\
\hline $\mathrm{O}_{1}$ amplitude at east. bound. (\%) & 97 & 106 & 102 & 97 & 98 & 95 \\
\hline $\mathrm{O}_{1}$ phase at east. bound. $\left({ }^{\circ}\right)$ & -2.8 & -7.2 & -4.7 & 1.0 & 0.9 & -0.4 \\
\hline $\begin{array}{l}\text { addition of water level at } \\
\text { west.bound. (m) }\end{array}$ & -0.012 & 0.004 & 0.005 & 0.004 & 0.004 & 0.005 \\
\hline bottom drag coefficient $\left(\times 10^{-3}\right)$ & 3.1 & 3.9 & 3.9 & 4.8 & 4.3 & 4.3 \\
\hline
\end{tabular}

Calculations using the optimized parameters were then run, and the cost functions for tidal elevation, current, and salinity were calculated using the observed and modelled results for each optimization case.

The cost functions for tidal elevation, current, and salinity $\left(J_{E}, J_{C}\right.$, and $J_{S}$, respectively) are defined as

$$
\begin{gathered}
J_{E}=\sum_{n 1, t} \frac{\left(E_{n 1, t}^{O}-E_{n 1, t}^{M}\right)^{2}}{R_{n 1, t}^{E}}, \\
J_{C}=\sum_{n 2, t} \quad \frac{\left(U_{n 2, t}^{O}-U_{n 2, t}^{M}\right)^{2}}{R_{n 2, t}^{U}}+\sum_{n 2, t} \frac{\left(V_{n 2, t}^{O}-V_{n 2, t}^{M}\right)^{2}}{R_{n 2, t}^{V}}, \\
J_{S}=\sum_{n 3, t} \frac{\left(S_{n 3, t}^{O}-S_{n 3, t}^{M}\right)^{2}}{R_{n 3, t}^{S}},
\end{gathered}
$$

where $E, U, V$, and $S$ are the elevation, eastward and northward velocities, and salinity, respectively; the superscript $O$ represents observational data measured for their hourly mean zonal and meridional components; the superscript $M$ represents the model's equivalents; and the subscripts $\mathrm{n} 1, \mathrm{n} 2, \mathrm{n} 3$, and $\mathrm{t}$ indicate measurement identities ( $\mathrm{n} 1=5, \mathrm{n} 2=$ $3, \mathrm{n} 3=9$ ) and temporal indices, respectively. Data at $0.5 \mathrm{~m}$ from the surface for salinity and 5 $\mathrm{m}$ for tidal currents were extracted from the model results. The number of the stations where salinity was measured was 16 as shown in Figure 1c, while we used salinity data at stations 4 to 9 and 11 to 13 which are located in the region where the reproduction of salinity are needed. We used every 1 hour data for 20 days (10-30 December 2007). The error variances $\left(R^{E}\right.$, $R^{U}, R^{V}, R^{S}$ ) are assumed here to be the same as the data variance. The assumption is based on the adjustment of $R$, according to the fundamental rule of data assimilation that cost function $J$ should be the same order as degrees of freedom [1]. Menemenlis [8] showed that three cases which error variance is equal to the data variance, equal to the variance of the model-data difference and proportional to it, give similar estimates.

The cost functions of the tidal currents significantly decreases in all of the optimization cases (Table 4), with a notable and substantial decrease shown in the case that considered only salinity in the formulation of the Green's functions matrix (optimization D). The cost func- 


\section{Journal of Advanced Simulation in Science and Engineering}

tions for salinity decrease in all cases, but the amount of decrease is relatively small in the case that used only tidal elevation to generate the Green's functions matrix. Also, note the clear decreases in the cases that used tidal current to generate the Green's functions matrix (optimizations B-C). Although the cost functions of tidal elevation decrease in some cases and increase in others, the values in all cases were much smaller than those of tidal current and salinity, because the inconsistencies between the observed and modelled tidal elevations were not significant originally.

Table 4: Cost function and its reduction relative to the baseline experiment

\begin{tabular}{llll}
\hline & Cost functions & & \\
\cline { 2 - 4 } Case & tidal elevation & Tidal currents & salinity \\
\hline Baseline & 227 & 1961 & 4200 \\
Optimization A & $191(16 \% \downarrow)$ & $1415(16 \% \downarrow)$ & $4097(2 \% \downarrow)$ \\
Optimization B & $304(34 \% \uparrow)$ & $981(50 \% \downarrow)$ & $3856(8 \% \downarrow)$ \\
Optimization C & $185(19 \% \downarrow)$ & $1022(48 \% \downarrow)$ & $3901(7 \% \downarrow)$ \\
Optimization D & $307(35 \% \uparrow)$ & $1087(45 \% \downarrow)$ & $3760(10 \% \downarrow)$ \\
Optimization E & $303(33 \% \uparrow)$ & $1100(44 \% \downarrow)$ & $3792(10 \% \downarrow)$ \\
Optimization F & $266(17 \% \uparrow)$ & $1112(43 \% \downarrow)$ & $3810(9 \% \downarrow)$ \\
\hline
\end{tabular}

\section{Parameter optimization using Green's functions}

The river plume calculated using the optimized parameter (optimization C) is shown in Figure 3. The low-salinity area indicated by dark shading moves southward during the ebb tide, and moves toward the east until low tide. It then moves west after low tide, because the tidal currents are directed to the west during the flood tide. The dark shading area disappears from the model domain until the next ebb tide comes. The changing low-salinity area modelled here is qualitatively consistent with the results of field observations in this area [12], and the next paragraph gives the evaluation of the consistency.

Figure 4 shows the improvement in the reproducibility of the river plume by the optimization. The phase of the tidal elevations and the amplitude of the tidal currents after optimization are closer to the observed results than the values in the baseline experiment. The mean root-mean-square (RMS) errors between the optimized model results and observations for the tidal elevations at five stations and currents of two components at three stations every 1 hour between $10^{\text {th }}$ and $30^{\text {th }}$ December 2007, are $0.12 \mathrm{~m}^{\text {and }} 0.11 \mathrm{~ms}^{-1}$, respectively. The phase of the minimum of salinity at low tide and the range of the decrease in salinity, are also clearly improved after optimization. These improvements at some stations are probably the main 


\section{Journal of Advanced Simulation in Science and Engineering}

reason for the reductions in the cost functions for salinity. The mean root-mean-square (RMS) errors between optimized model results and observations for salinity every 1 hour between $10^{\text {th }}$ and $30^{\text {th }}$ December 2007, are 0.84 psu at the stations as same as these used to calculate cost function. It is important to remember, of course, the peaks of salinity in the model results did not perfectly agree with the observed results, but the reproducibility of the model was not bad as compared to the previous study which modeled river plumes (e.g. [10, 11]).

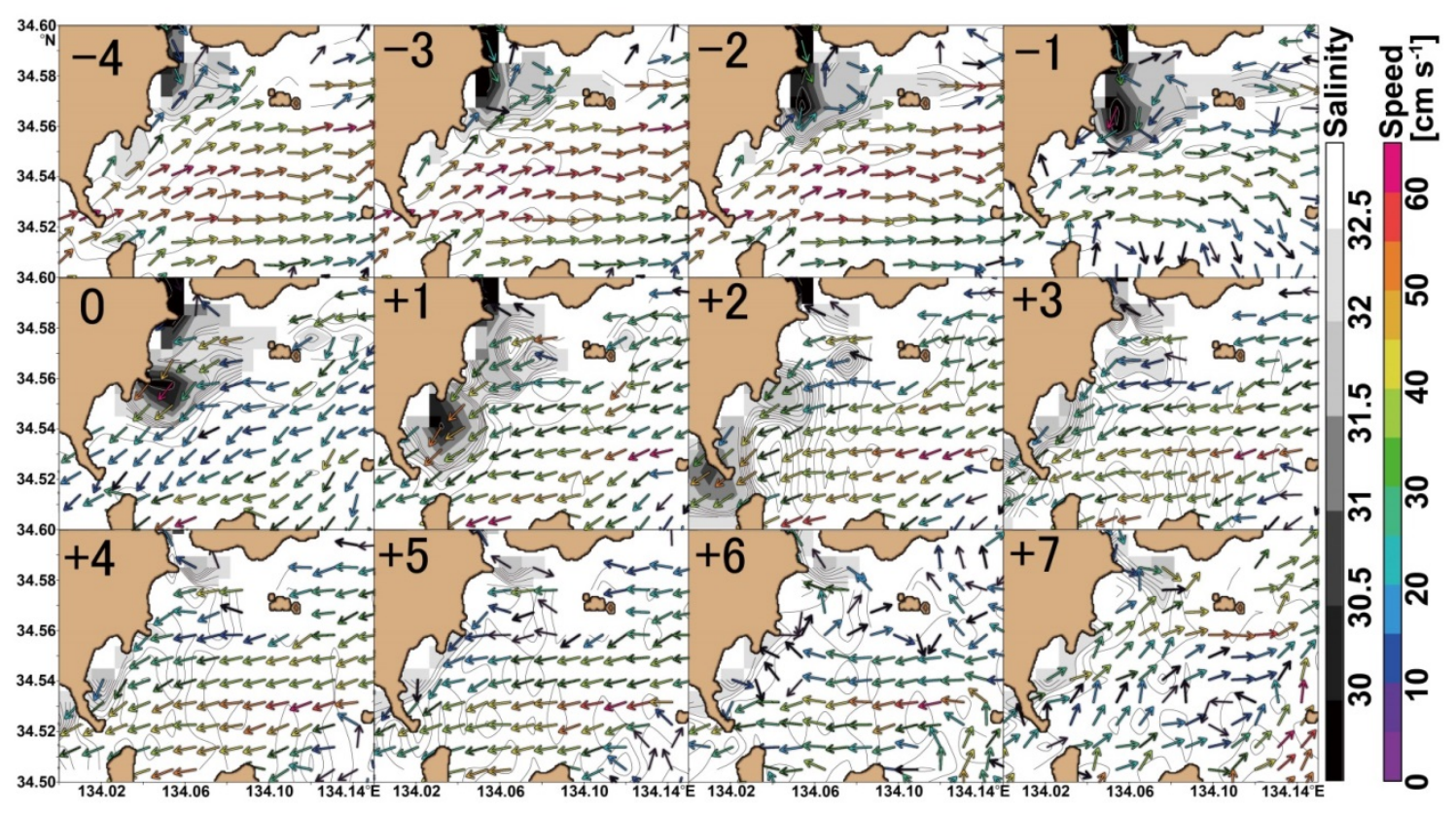

Figure 3: Horizontal distributions of salinity and vector plot of tidal currents $\left(\mathrm{cm} \mathrm{s}^{-1}\right)$ from 02:00 to 13:00 on $26^{\text {th }}$ December 2007, modelled using optimized parameter (optimization C). The numbers on each panel indicate the time in hours from low water at Uno (shown in Figure $1 b)$. 

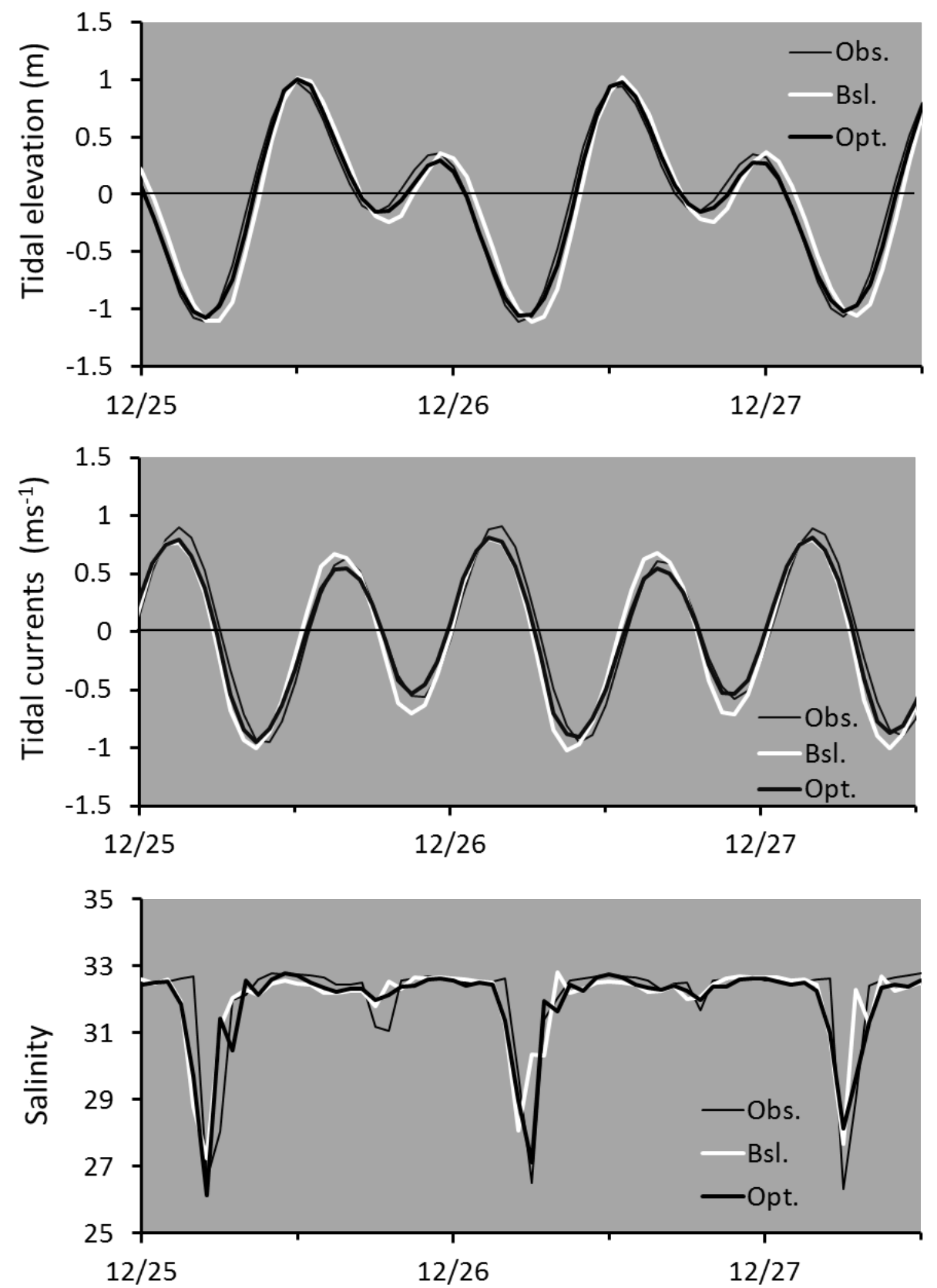

Figure 4: Temporal variations of (a) tidal elevations (m), (b) tidal currents, and (c) salinity from 00:00 on $25^{\text {th }}$ to 12:00 on $27^{\text {th }}$ December 2007 at the stations shown in Fig. 1(b) and 1(c) by star marks. Positive and negative values of tidal currents represent eastward and westward movements, respectively. The black, white, and bold black lines indicate the observed results and those calculated for the baseline case and optimization $\mathrm{C}$, respectively. 


\section{Summary and discussion}

This study examined the applicability of the Green's functions approach to a coastal model with smaller spatial scale than used in previous studies. The cost functions of tidal elevation and current reduced after optimization of the model parameters, suggesting that the Green's functions improved model performance. The cost function of salinity at the river mouth also reduced following the optimization of tidal elevation and current, and the pulsed changes of salinity and the tidal cycle of the river plume were well reproduced.

We also compared the optimized results in cases using tidal elevation, current, and salinity separately to generate the Green's functions matrix. The reproducibility of the pulsed decrease in salinity improved when the optimization considered tidal elevation and current data. The accuracy of the tidal current was also improved in the case that used only salinity to generate the Green's functions matrix. These findings suggest that salinity variations were caused mainly by tidal currents - which show linearity — and that the Green's functions approach can accurately reproduce these variations in salinity, despite their strong nonlinearity.

Here, we only applied tidal elevation at the lateral boundaries of the model to simulate the river plume under the assumption that it is mainly controlled by tidal elevation and currents, and the model successfully reproduced the river plume. We recognize, however, that the minor inconsistencies between the modelled and observed results imply that the driving force other than tidal currents, such as wind and density currents, may influence on temporal changes in salinity. The future simulation of these currents, which are typically 1-2 orders of magnitude smaller than the tidal currents and also irregular, will require the optimization of their related model parameters in addition to those related to tidal currents.

\section{Acknowledgement}

We sincerely appreciate the insightful advice of emeritus professor Fujiwara regarding the availability of topographic and tidal harmonic constants data for the Seto Inland Sea. We also thank the two anonymous reviewers and editor for their helpful comments.

\section{References}

[1] T. Awaji, M. Kamachi, M. Ikeda, Y. Ishikawa: Data assimilation, Kyoto University Press, (2009), 284 pp.

[2] J. D. Bricker, I. Okabe, A.Nakayama: Behavior of a Small Pulsed River Plume in a Strong Tidal Cross-Flow in the Akashi Strait, Environmental Fluid Mechanics, 6 (2006), 203-225.

[3] A.F. Blumberg and G.L. Mellor: A description of a three-dimensional coastal ocean circulation model. In: Heaps, N.S. (Ed.), Three Dimensional Coastal Ocean Models, 


\section{Journal of Advanced Simulation in Science and Engineering}

Coastal and Estuarine Sciences Vol. 4, American Geophysical Union, Washington (1987), 208 pp.

[4] P-H. Chang, X. Guo, H. Takeoka, A Numerical Study of the Seasonal Circulation in the Seto Inland Sea, Japan, Journal of Oceanography, 65 ( 2009) , 721 - 736.

[5] N. Hirose: Inverse estimation of empirical parameters used in a regional ocean circulation model, J. Oceanogr., (2012), doi:10.1007/s10872-011-0041-4.

[6] S. Kobayashi, J. H. Simpson, T. Fujiwara, K. J. Horsburgh: Tidal stirring and its impact on water column stability and property distributions in a semi-enclosed shelf sea (Seto Inland Sea, Japan), Continental Shelf Research, 26 (2006), 1295-1306.

[7] G.L. Mellor, S. Hakkinen, T. Ezer, R. Patchen: A generalization of a sigma coordinate ocean model and an intercomparison of model vertical grids, In: Pinardi, N., Woods, J.D. (Eds.), Ocean Forecasting: Conceptual Basis and Applications, Springer, (2002), 55-72.

[8] D. Menemenlis, D. Fukumori, T. Lee: Using Green's functions to calibrate an ocean general circulation model, Mon. Weather Rev, 133 (2005), 1224-1240.

[9] J.-H. Moon, N. Hirose, A. Morimoto: Green's function approach for calibrating tides in a circulation model for the East Asian marginal seas, J. Oceanogr, (2012), DOI 10.1007/s10872-011-0097-1.

[10] C. K. O’Neill, J. A. Polton, J. T. Holt, E. J. O’Dea: Modelling temperature and salinity in Liverpool Bay and the Irish Sea: sensitivity to model type and surface forcing, Ocean Sci. (2012), 8, 903-913.

[11] J. Pan, Y. Gu, D. Wang: Observations and numerical modeling of the Pearl River plume in summer season, J. Geophysical Res. (2014), 119(4), 2480-2500.

[12] S. Takagi, Y. Shimizu, K. Kusaka, S. Kobayashi, et al.: Evaluation of riverine DIN in the nori Pyropia cultivated in coastal sea areas using nitrogen stable isotopes, Nippon Suisan Gakkaishi, 79:6 (2013), 1002-1008. 